\title{
Discharge coefficient behaviour in presence of four perforated plates flow conditioners - Numerical investigation Part 1-
}

\author{
Boualem Laribi ${ }^{1, \mathrm{a}}$ and Abdellah Abdellah $\mathrm{Hadj}^{2}$ \\ ${ }^{1}$ FIMA Laboratory, University of Djillali Bounaama, Khemis Miliana, Algeria \\ ${ }^{2}$ LMPEM Laboratory, University of Feres Yahia, Medea, Algeria
}

\begin{abstract}
This paper present a part 1 of numerical experimentation of the behaviour of the discharge coefficient and the effect of four perforated plates flow conditioners on the discharge coefficient for flow measurement accuracy. Three of the plates are described by the Standard ISO5167 and the fourth one is proposed for study. In this part 1, the disturber used is $90^{\circ}$ double bend in perpendicular planes while in the part 2 the flow is subject to disturbers namely $30 \%$ and $50 \%$ closed valves. The turbulent flow is examined in conduit with an inner diameter of $\mathrm{D}=100 \mathrm{~mm}$. The diameter of orifice meters are respectively $\mathrm{d}=50,60,70$ and $75 \mathrm{~mm}$ which done for $\beta=\mathrm{d} / \mathrm{D}$ respectively the values of $0.5,0.6,0.7$ and 0.75 . The orifice meters are located in conduit at different stations $\mathrm{z} / \mathrm{D}$ downstream the disturber. The flow is examined with air at Reynolds number $\mathrm{Re}=2.5 \times 10^{5}$. The software used for this simulation is ANSYS package with $\mathrm{k}-\varepsilon$ like turbulence model. A numerical investigation was done before (CIM 2013) with the same conditions but without perforated plates and the results showed that when the diameter of the orifice meter increases the shifts deviation of the discharge coefficient increases this causes a great error in flow measurement. Contrary, when the diameter of the orifice meter decreases the shifts deviation in the discharge coefficient decreases and the error in flow measurement is reduced. These results are the same with the two disturbers $90^{\circ}$ double bend and $50 \%$ closed valve used separately in conduit. In this paper the results showed that the perforated plates have significantly reduced the error on the discharge coefficient. Indeed, the errors recorded downstream disturbers are superior to $2 \%$. Downstream the perforated plates used separately the errors on the discharge coefficient are reduced to a value inferior to $1 \%$ for the four plates. It is noted that the standards ISO5167 and AGA3 stipulate that the error on the discharge coefficient $\mathrm{Cd}$ must be less than $\pm 0.5 \%$ for better flow measurement accuracy. By comparing our results with this condition we found that the results obtained with the four plates are substantially reduced especially downstream station $z=25 \mathrm{D}$ ( $\mathrm{z}=20.5 \mathrm{D}$ downstream flow conditioners). However the fourth proposed plate with its high porosity produces less losses pressures than those of the other three plates. This is good condition of exploitation for some installation where high losses pressures are not tolerated.
\end{abstract}

\section{Introduction}

Flow meters flowmeters are calibrated and characterized under fully developed pipe flow conditions. Disturbances such as swirl, cross-flow, and asymmetry can produce relevant metering errors [1].

In practical applications, the fully developed conditions can hardly be obtained. In fact, flow disturbances are caused by the elements of the piping itself, such as bends, Tee and valves. Theoretically, it could be possible to reduce the influence of these disturbances using an adequate straight of pipe between the disturbers and the flowmeter. In practice, due to the reduced dimensions of the piping, it is useful to use flow conditioners $[1,2]$. The flow conditioners used in the oil and gas industry such as the Etoile, the tube bundle, the
Sprinkle, the Zanker and the perforated plate, have been described in the international standards [1].

The Etoile flow straightener has been the subject of several studies from Wauters and al [3], Laws and al [4] to Laribi and al $[5,6]$.

Standards ISO 5167[1] and AGA-3[2] define a satisfactory condition on the discharge coefficient errors while high accuracy about $\pm 0.5 \%$ in mass flow measurement is required, disturbers in the flow introduced by contractions, bends, valves and other components introduce errors more 3\% [3].

Flow conditioners have as a main role the acceleration of the formation of the established flow, i.e., obtaining a fully developed velocity and turbulent intensity profiles [7] over a length as reduced as possible in order to

\footnotetext{
a boualemlaribi@yahoo.com
} 
attenuate the disturbance of the flow other wise to reduce the error on flow measurement $[8,9]$.

Our paper is a numerical analysis, with a commercial CFD code [10], which examines the effect of disturber like a $90 \square$ double bend in perpendicular planes [11] on the discharge coefficient errors. Four perforated plates are examined to show the capability of plate to reduce this error. Three of the perforated plates are described in the standard ISO 5167 namely the NOVA, the NEL and the ZANKER. The fourth one is a new design and proposed plate. The study is focused on conduit with diameter D of $100 \mathrm{~mm}$ at a Reynolds number of $2.5 \times 105$. The measuring stations of the discharge coefficient are respectively $1.5 \mathrm{D}, 7 \mathrm{D}, 12 \mathrm{D}, 17.5 \mathrm{D}, 25 \mathrm{D}, 35 \mathrm{D}$ downstream the disturber.

\section{Experimental simulation}

\subsection{Conduit}

The flow in the conduit, Fig. 1, is produced by air with a Reynolds number $\mathrm{Re}=2.5 \times 105$. The air leads from the entrance on the length $10 \mathrm{D}$ for good flow conditions upstream disturber. The disturber is installed at 10D from the entrance. The four plates flow conditioners are used separately at station $\mathrm{z} / \mathrm{D}=14.5$ downstream of the entrance of conduit (4.5D downstream disturber). The measuring stations of the discharge coefficient are respectively $1.5 \mathrm{D}$ downstream disturber and $2.5 \mathrm{D}, 7.5 \mathrm{D}$, 13D, 20.5D, 30.5D and 91.5D downstream flow conditioners.

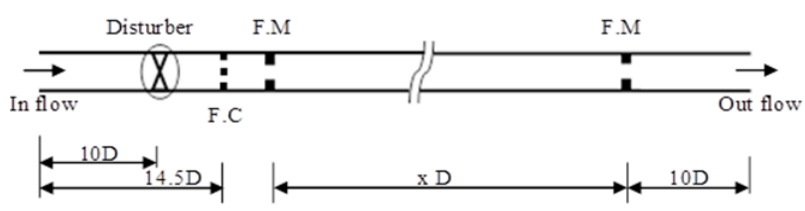

Figure 1. Facility for numerical simulation

\subsection{Perforated plates used}

The flow in The four perforated plates, P1, P2, P3 and P4 used in this simulation are described as bellow, Fig.2,

$\mathrm{P} 1$ : NOVA [1] flow conditioner is provided in our case

- A central hole of diameter $0.226 \mathrm{D}$

- A ring of 8 holes of diameter $0.163 \mathrm{D}$ on a pitch circle diameter of $0.5 \mathrm{D}$

- A ring of 16 holes of diameter $0.124 \mathrm{D}$ on a pitch circle diameter of $0.85 \mathrm{D}$

The plate thickness is $0.125 \mathrm{D}$ with a pressure loss coefficient approximately equal 2.0 .

P2 : NEL PLATE [1] flow conditioner is provided

- A ring of 4 holes of diameter $0.10 \mathrm{D}$ on a pitch circle diameter of $0.18 \mathrm{D}$

- A ring of 8 holes of diameter $0.16 \mathrm{D}$ on a pitch circle diameter of $0.48 \mathrm{D}$
- A ring of 16 holes of diameter $0.12 \mathrm{D}$ on a pitch circle diameter of $0.86 \mathrm{D}$

The plate thickness is $0.12 \mathrm{D}$ with a pressure loss coefficient approximately equal 3.2.

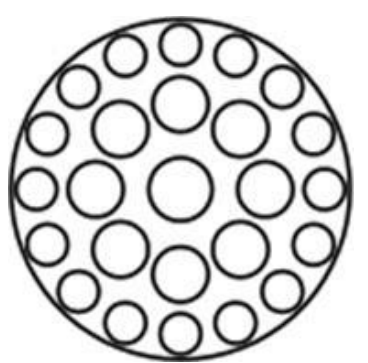

NOVA F.C. (P1)

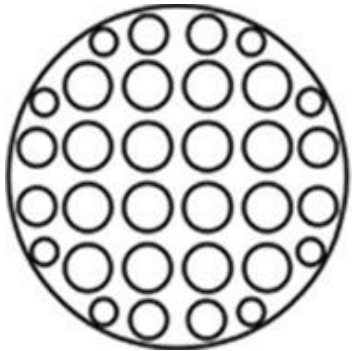

ZANKER F.C. (P3)

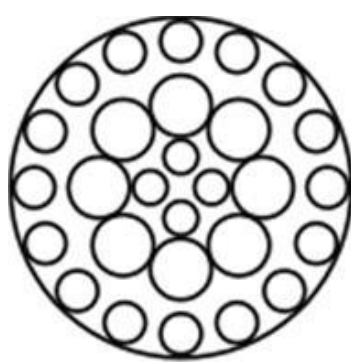

NEL F.C. (P2)

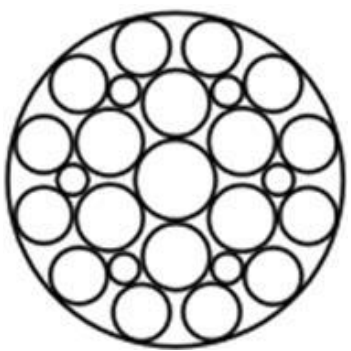

NEW PLATE F.C. (P4)
Figure 2. The perforated plates used

P3 : ZANKER PLATE [1] flow conditioner is provided

- A ring of 4 holes of diameter $0.141 \mathrm{D}$ on a pitch circle diameter of $0.25 \mathrm{D}$

- A ring of 8 holes of diameter $0.139 \mathrm{D}$ on a pitch circle diameter of $0.56 \mathrm{D}$

- A ring of 4 holes of diameter $0.136 \mathrm{D}$ on a pitch circle diameter of $0.75 \mathrm{D}$

- A ring of 8 holes of diameter $0.110 \mathrm{D}$ on a pitch circle diameter of $0.85 \mathrm{D}$

- A ring of 8 holes of diameter $0.077 \mathrm{D}$ on a pitch circle diameter of $0.90 \mathrm{D}$

The plate thickness is $0.125 \mathrm{D}$ with a pressure loss coefficient approximately equal 3.0.

P4 : NEW PLATE flow conditioner is provided

- A central hole of diameter 0.24D

- A ring of 6 holes of diameter $0.20 \mathrm{D}$ on a pitch circle diameter of $0.50 \mathrm{D}$

- A ring of 6 holes of diameter 0.09D on a pitch circle diameter of $0.60 \mathrm{D}$

- A ring of 12 holes of diameter $0.17 \mathrm{D}$ on a pitch circle diameter of $0.80 \mathrm{D}$ 
The plate thickness is $0.125 \mathrm{D}$.

\subsection{Basic equations}

The general equation used in CFD and by Fluent code is given by:

$$
\frac{\partial(\rho \emptyset)}{\partial t}+\operatorname{div}(\rho \varnothing \vec{U})=\operatorname{div}\left(\Gamma_{\phi} \operatorname{grad} \emptyset\right)+S_{\varnothing}
$$

Where $\phi$ is the general dependent variable which can be the mean velocity, the turbulent kinetic energy $\mathrm{k}$ or the rate of dissipation of the turbulent kinetic energy $\varepsilon$.

$\mathrm{S} \phi$ is the term source of the variable $\phi$

$\Gamma \phi$ is the coefficient of diffusion of $\phi$

The k- $\varepsilon$ model is used like turbulent model. It is based on the Boussinesq hypothesis. It is a semi-empirical model. Two transport equations are used, one for the turbulence kinetic energy $\mathrm{k}$ and the other for its dissipation rate $\varepsilon$. The reader can found more information in [12].

\subsection{Variation of discharge coefficient}

For testing the effect of disturbers on the discharge coefficients of the orifice meters, the shift deviation for the discharge coefficient $\Delta C d(\%)$ is calculated by using the difference pressure $\Delta P$ obtained by the simulation at different locations of the orifice meter in the pipe and $\triangle P o$ at the same time at station $\mathrm{z} / \mathrm{D}=97$ were the flow is supposed fully developed. Eq. 2 shows the calculus formula

$$
\Delta C d(\%)=\sqrt{\frac{\Delta P o}{\Delta P}}-1
$$

The difference pressure is calculated according to the standard ISO 5167 at D upstream and D/2 downstream the orifice meter. This formula was applied for all orifice plates with the disturber.

\section{Results and discussion}

The examination of the Fig.3 to Fig.6 shows the discharge coefficient error in the case of a $90^{\circ}$ double bend in perpendicular planes used with the four flow conditioners. The flow meter is located at different stations downstream the flow conditioners. The ISO 5167 limits $\pm 0.5 \%$ of the discharge coefficient is included for comparison.

Fig. 3 shows the discharge coefficient errors at several stations downstream $90^{\circ}$ double bend in perpendicular planes with the NOVA F.C on line. At $\mathrm{z} / \mathrm{D}=1.5$ we register an error values around $-2 \%$ for the orifice meters with $\beta=0.7$ and 0.75 and a minimum values around $1 \%$ for $\beta=0.5$ and 0.6 . These results are in good agreement with results obtained in before research works and exposed in the International Congress of Metrology 2013 [8]. We can see the effectiveness of the NOVA flow conditioner at station $\mathrm{z} / \mathrm{D}=7 \quad(2.5 \mathrm{D}$ downstream the NOVA F.C.) to reduce these errors around $\pm 1 \%$ for all flow meters except for $\beta=0.75$ where the error closed $5 \%$ at station $\mathrm{z} / \mathrm{D}=7$. The best results where the discharge coefficient errors are closed the ISO limits are obtained for $\beta=0.7$ in all stations downstream the NOVA F.C.

Fig. 4 shows the discharge coefficient errors at several stations downstream $90^{\circ}$ double bend in perpendicular planes with the NEL F.C on line. At $\mathrm{z} / \mathrm{D}=1.5$ we register an error values around $-2 \%$ for the orifice meters with $\quad \beta=0.6$ and a minimum values around $-0.5 \%$ for $\beta=0.7$ and $\beta=0.75$. We can see the effectiveness of the NEL flow conditioner at station $\mathrm{z} / \mathrm{D}=17$ (12.5D downstream the NEL F.C) to reduce these errors around $\pm 1 \%$ for all flow meters.

The best results where the discharge coefficient errors are closed the ISO limits are obtained for all the flow meters except for $\beta=0.6$ where the error is around $1 \%$ at station $z / D=25$ downstream. For the NEL C.F it seems all deviations on the discharge coefficient are greater than $0.5 \%$ as stipulate by the standards.

Fig. 5 shows the discharge coefficient errors at several stations downstream $90^{\circ}$ double bend in perpendicular planes and the ZANKER F.C on line. At $\mathrm{z} / \mathrm{D}=1.5$ we register an error values around $-5 \%$ for the orifice meters with $\beta=0.6$ and a minimum values around $-0.5 \%$ for $\beta=0.75$. We can see the effectiveness of the ZANKER flow conditioner at station $\mathrm{z} / \mathrm{D}=17$ (12.5D downstream the ZANKER F.C) to reduce these errors around $\pm 1 \%$ for all flow meters. The best results where the discharge coefficient errors are closed the ISO limits are obtained for all the flow meters where the error is around $1 \%$.

For the ZANKER C.F it seems that all deviations on the discharge coefficient are greater than $\pm 0.5 \%$ as stipulate by the standards. For station $\mathrm{z} / \mathrm{D}=7$ downstream the disturber we register an error around $-6 \%$ for $\beta=0.7$ and around $-8 \%$ for $\beta=0.75$. For this plate all the values of the discharge coefficient are out of ISO limits.

Fig. 6 shows the discharge coefficient errors at several stations downstream $90^{\circ}$ double bend in perpendicular planes with the new plate F.C on line. At $\mathrm{z} / \mathrm{D}=1.5$ we register an error values around $-2 \%$ for all orifice meters except with $\beta=0.75$ where the error is closed the ISO limits. We can see the effectiveness of the new plate F.C at station $\mathrm{z} / \mathrm{D}=13$ and $25(8.5 \mathrm{D}$ and $21.5 \mathrm{D}$ downstream F.C) to reduce these errors around $\pm 0.5 \%$ for flow meter with $\beta=0.70$. The best results where the discharge coefficient errors are closed the ISO limits are obtained for all the flow meters except for $\beta=0.75$ where the error is around $1.5 \%$ at station $\mathrm{z}=25 \mathrm{D}$. 


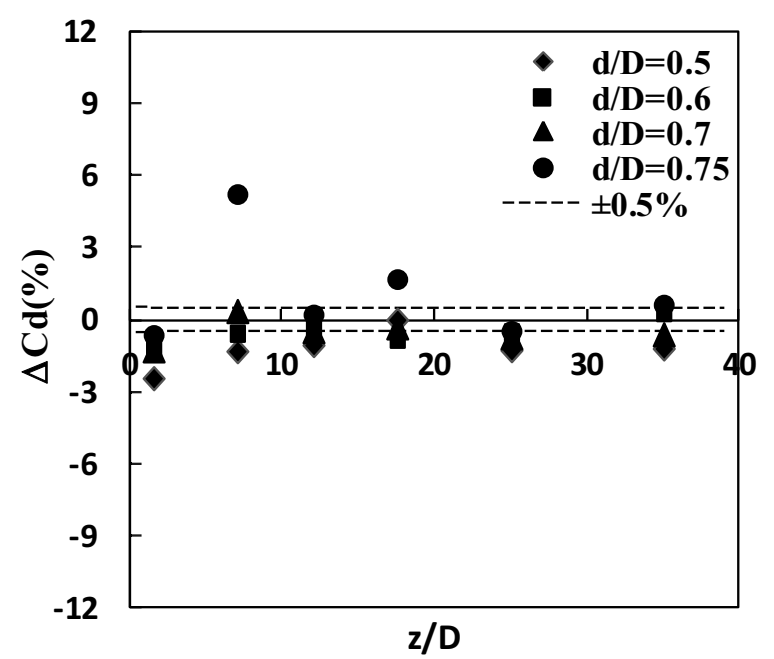

Figure 3 : Discharge coefficient errors with the NOVA F.C and double bend on line

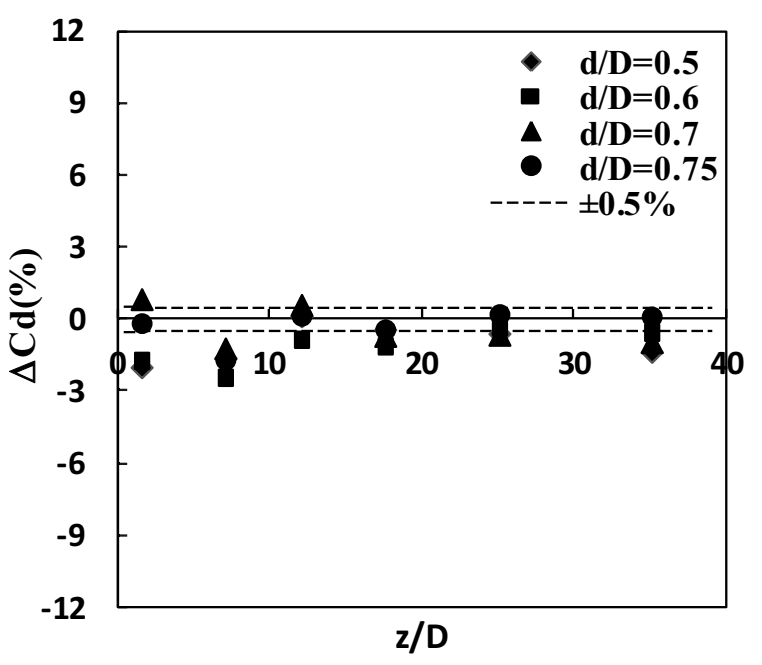

Figure 4 : Discharge coefficient errors with the

NEL F.C and double bend on line

\section{Conclusion}

The examination of the results shows that the double bend produces an error, generally in the case of no flow conditioners, less than $3 \%$.

Downstream the perforated plates used separately the errors on the discharge coefficient are reduced to a value inferior to $1 \%$ for the four plates. It is noted that the standards stipulate that the error on the discharge coefficient $\mathrm{Cd}$ must be less than $0.5 \%$ for better flow measurement accuracy.

We show that the perforated plates have significantly reduced the error on the discharge coefficient.

Also these results show that the orifice meters are very sensitive to the type of flow conditioners used. Indeed, there are some restrictions to use a particular flow conditioner with a particular orifice meter. Based on the results we see that the NOVA FC is better suited with the

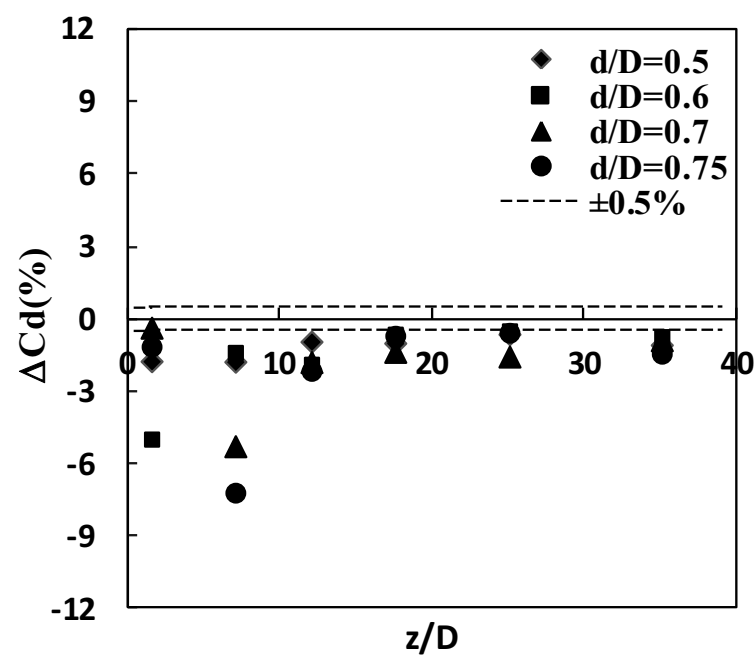

Figure 5 : Discharge coefficient errors with the ZANKER F.C and double bend on line

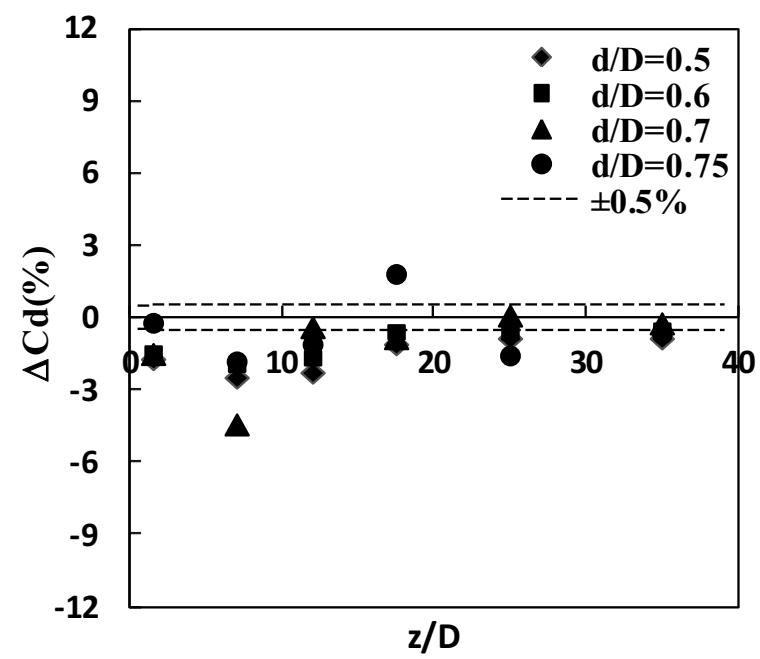

Figure 6 : Discharge coefficient errors with the

New plate F.C and double bend on line

orifice meter with $\beta=0.7$ where the error on the discharge coefficient is within the limits set by the standards. The NEL FC is better adapted with the orifice meter which $\beta=0.75$.

The ZANKER C.F is poorly adapted than these other flow meters but the error on the discharge coefficient $\mathrm{Cd}$ is around of $\pm 1 \%$.

Looking at these results obtained by the proposed new plate we see that it fits better with the orifice meter which $\beta=0.70$ where the error on the discharge coefficient is around the values set by the standards.

By comparing our results with this condition we found that the results obtained with the four plates are substantially reduced especially downstream station $z=25 D \quad(z=20.5 D$ downstream flow conditioners). However the fourth proposed plate with its height 
porosity produce less losses pressures than those of the other three plates. This is good condition of exploitation for some installation where height losses pressures are not tolerated.

Views these differences of these results obtained we thought to undertake another series of numerical works with other disturbers to clarify this divergence. This will be the subject of Part 2.

\section{References}

1. ISO 5167, Measurement of fluid flow by means of orifice plates nozzles and ventury tubes inserted in circular cross section conduits running fuel, (2003)

2. AGA-3, 'Orifice Metering of Natural Gas and the Related Hydrocarbone Fuels", (1980)

3. Yeh, T.T and Mattingly, G. E, "Flow meter installation effects due to a generic header". NIST Technical note 1419 , (1996)

4. Gallagher J. Flow conditioning, Why, What, When and where, Siminarion Avanzado de Medition de Flujo de fluidos, Aguascalientes, Ags, Mexico, September 2009 5. Rans, R. \& al , Flow Conditioning and Effects on Accuracy for Fluid measurement, 7th East Asia Hydrocarbon Flow Measurement Workshop 5th -7 th, Malisia, March (2008)

6. Laribi B. and al, Numerical simulation of flow development downstream four perforated plates for flow measurement accuracy, ASME Fluids Engineering Division Summer Meeting, FEDSM'14, Chicago, USA, July 2014.

7. Bukhari Manshoor and Amir Khalid,' Numerical Investigation of the Circle Grids Fractal Flow Conditioner for Orifice Plate Flowmeters', Applied Mechanics and Materials, Vol.229-231, pp. 700-704, Nov 2012.

8. Laribi B. and Ait-Amrane A, 'Numerical analysis of the discharge coefficient with disturbers for flowmetring accuracy on flow measurement', 16th International Metrology Congress - Paris, October 2013.

9. Darin L. \& Bowles E. B., Conditioning On Gas Measurement, Pipeline \& Gas Journal, PP 59-62 (2008)

10. Fluent v6.3, Fluent incorporated, Journal Centerra source park, USA, 2006.

11. B. Laribi and al, Numerical investigation of contribution of three flow conditioners in the development and establishment of turbulent flows, Proceedings of ASME 2010 3rd joint US-European Fluids Engineering Summer Meeting, and 8th International Conference on Nanochannels, Microchannels and Minichannels, FEDSM2010ICNMM2010, Montreal, Canada, 2010.

12. B. Laribi and al, Numerical investigation of turbulent models in the development and establishment of turbulent flows with flow conditioners, Proceedings of ASME 2010 3rd joint US-European Fluids Engineering Summer Meeting, and 8th International Conference on Nanochannels, Microchannels and Minichannels, FEDSM2010-ICNMM2010, Montreal, Canada, 2010. 